\title{
Student Retention through Customized Service Processes
}

\author{
Reinhard Jung, Jessica Kochbeck, Annett Nagel \\ Chair of Business Informatics and Enterprise Communications Systems University \\ of Duisburg-Essen \\ Universitaetsstrasse 9,45141 Essen, Germany \\ \{reinhard.jungljessica.kochbecklannett.nagel\}@icb.uni-due.de \\ www.kom.wiwi.uni-due.de
}

\begin{abstract}
Due to the Bologna declaration and the subsequent switch to the bachelor/master system, student mobility is rising and competition among universities across Europe becomes intense. Furthermore, students are demanding comfortable information and communication solutions. Hence, universities are required to align educational- and serviceprocesses more closely to their students. This paper presents an innovative approach to adapt modern concepts of Customer Relationship Management (CRM) to institutions of higher education in order to retain students at their university. Furthermore, an architecture is presented which is capable of integrating university legacy systems with state of the art CRM technology.
\end{abstract}

\section{Introduction}

Before the implementation of the Bologna declaration [1], Customer Relationship Management (CRM) was not imminent in most European institutions of higher education and thus economically inefficient. In the past, an educational process typically started with the enrollment at a university and generally ended, several years later, when the student received the final degree (e.g. a diploma) at the same institution. Switching universities during the studies implicated severe frictions because already completed exams have very often not been acknowledged by the new university.

The implementation of the Bologna declaration across Europe's universities over the past years triggered the transformation from monolithic study programs to a dual system: Two formally separated courses of study, i.e. bachelor and master program, result in respective academic degrees. Besides prescribing this modular structure, one of the core intentions of the Bologna declaration was to increase student mobility sig-

Please use the following format when citing this chapter:

Jung, R., Kochbeck, J., Nagel, A., 2008, in IFIP International Federation for Information Processing, Volume 286; Towards Sustainable Society on Ubiquitous Networks, eds. Oya, M., Uda, R., Yasunobu, C., (Boston: Springer), pp. 221-231. 
nificantly. Universities are obliged to accept graduate students from other universities based upon the same formal criteria they apply to their "own" graduate students (e.g. "must have a bachelor degree and a bachelor diploma grade of at least ..."). The conference of Swiss university presidents adopted a directive in 2005 stating that students with a corresponding bachelor degree have to be accepted for graduate studies (master programs) without requiring any further prerequisites [2, p. 1].

Research has been done regarding student mobility in the USA (e.g. [3]). The research focus on the mobility aspect in Europe was on the students willingness and ability to spend semesters abroad (e.g. exchange programs) and their later choice of employment [4]. Currently, first empirical results on the mobility bachelor and master studies in Germany are available [5]: $77 \%$ of the students graduating from a bachelor program apply directly for another program and approximately $75 \%$ of them do not switch universities. Only $25 \%$ are moving to another university. Considering that these results are from a transitional period with yet unknown acceptance of bachelor degrees in the corporate world, we can expect, that student mobility following the bachelor degree - based upon the identified $25 \%$ - will be increasing.

Simultaneously, the subsidization of the universities (in Germany) changed significantly. Due to the unfortunate financial situation in most of the states (e.g. [6, pp. 5]), government subsidies are now bound to performance measure (e.g. number of students enrolled, number of graduates).

In summary, institutions of higher education are now much more dependent on higher capacity utilization in order to retain their subsidies or get additional funding. Under the assumption of higher student mobility after completed bachelor studies, there is a need for action concerning customer (student) retention. In this paper the term "university customer" is defined as: A person that is enrolled for at least one of study programs of the institution under consideration. The extension of this definition includes a wide spectrum of students: prospective and actual undergraduate and graduate students, students in shorter courses of study (e.g. certificate courses) as well as $\mathrm{Ph} . \mathrm{D}$. students and post-docs. The definition does not necessarily require that students are to pay tuition fees. Some of the German states still run their universities without tuition fees.

Today's students expect, besides a good research and teaching reputation, a high quality of service. These expectations may have increased since the introduction of tuition fees. When additionally considering the increased mobility of graduate students, the need for action leaves the universities theoretically with two strategic options in order to retain their students which are know from the corporate world:

1. Retaining the customer by means of switching barriers. However, the Bologna process abolished these barriers.

2. The second strategy is to "design" the relationship with the students in a way that is rationally and/or irrationally perceived positive. It can be assumed, that this leads to higher contentedness and, as a consequence, to a lower churn rate [7, pp. 49].

Thus, the only viable strategy to achive student retention is strategy \# 2 . The literature refers to related activities by using the term Student Relationship Management [7, p. $56 ; 8$, p. $3 ; 9]$. 
The second strategy can be implemented by deploying different means, which are also used by corporations in their CRM programs:

1. Product quality: The high quality of an educational program results from a broad course offering and a high qualification and reputation of the respective faculty;

2. Service process quality: Professionalizing and individualizing the educational process imply the effect of a (ceteris paribus) more successful student retention and more effective acquisition of new students;

3. Image: Professional brand building.

The focus of this paper is on the second aspect. We are researching how (bachelor) student retention can be increased by means service process quality improvement.

\section{Short-comings of Today's Universities' Service Processes}

Service processes at universities are typically characterized by a division of labor. Involved organizations (student union, registrar's office, institutes/chairs, libraries, examination office etc.) supply their services mostly uncoordinated. Integrating the different services into one service process is left to the students who are bound by regulations and guidelines (conditions of study, examination regulations etc.). Most services at universities are delivered online, thus rendering the rightly criticized queues of waiting students [7] a thing of the past. Nevertheless, most universities do not offer truly integrated services. This state of affairs is aggravated by isolated and independent IT-Systems, e.g. registrar system, electronic university calendar, websites of the institutes with information on courses, electronic teaching platforms, systems for academic record administration, library systems and exam administration systems. A sample process could be as follows: Available courses in his or her main and minor subject are evaluated at the beginning of the term by the student; the electronic university calendar also highlights courses that have been successfully completed. Additional information on courses (e.g. exam dates), have to be gathered from the respective institutes websites. The student then chooses some of the courses but has to write necessary information down separately because the electronic university calendar does not offer a corresponding functionality. The next step is search for the courses within the different platforms (e.g. electronic teaching platform) and to subscribe to them. It might happen that some of the courses are not supported by the learning platform or are not online yet. During the semester recommended literature for the respective courses has to be searched for in (isolated) library systems and lent if available. Finally, the student has to obtain information on subscription deadlines for exams and finally use the exam administration system to subscribe for exams; these web-based systems are at best "integrated" by means of links to the respective login pages.

Improving such or similar situations requires the following steps: Data integration, so that all involved systems access one - at least logically centralized -consistent master data base including a centralized identity management system. Furthermore, it is necessary to seamlessly connect different service processes once they are initiated by students. Additionally, a portal has to be established enabling the students to access the various services of the university. 


\section{Related Work}

There are some publications available that deal with CRM at higher education institutions. In [10] a framework is presented aiming at the optimization of recruiting processes (recruitment of students) through data base marketing. Some papers deal with "student retention" (e.g. [11, 12]), whereby the main focus is not the retention of students between bachelor degree and master studies but a wide cause analysis of dropouts. The following publications are relevant with respect to our research goals:

- In [13] Kidwell et al. outline the first ideas regarding the transfer of e-business concepts to the educational sector. However, they do not provide a coherent framework.

- In his paper on service processes at the University of Mannheim (Germany) Heiling outlines a customers' perspective on the various independent and isolated customer relations a university maintains and elaborates on the frictions that causes on the students' side. He derives an architecture which connects the different IT systems by means of a middleware layer and complements that architecture with a central database [7].

- Kudrass proposes a hub-and-spoke architecture for the integration of heterogeneous databases in the university environment with a database as the central component [8].

An outline for an integrated architecture supporting CRM measures which focus on student retention cannot be found neither in Anglo-American nor in German research literature.

\section{Applying CRM Concepts to Universities}

One of the objectives of this paper is to apply CRM concepts to institutions of higher education and, basing on that, to derive an appropriate architecture for the typical IT landscape, i.e. a landscape comprising a considerable number of legacy systems.

In this section concepts from the "conventional" customer relationship management are adapted to the university environment.

\section{Customer process}

From the customers' point of view the customer process in this context is the whole educational process from enrollment to a first or second degree or even to a Ph.D. or a post-doctoral lecturing qualification. After graduation, this process can be extended by an alumni phase. The left hand side of Fig. 1 depicts an educational process from the student's perspective starting with the desire to take up studies towards the alumni phase including possible variants depending on decisions and events during that process. The universities' perspective on the right hand side shows the alignment of CRM actions to the customer process [14, p. 43]. As a means of modeling event-driven process chains [16, pp. 111] have been used.

\section{Customer value analysis}

The customer value analysis is utilized to estimate a client's business volume and contribution margin potential. For this purpose, possible transactions in a specific 
customer group have to be predicted. In the educational field, the customer value is subject of a prediction too. However, it cannot be represented by a monetary figure. Based on formal qualification, visible preferences, academic performance and intellectual potential of a person an indicator might be calculated. It's value can be used to predict which additional educational offerings of the university the student is likely to use. When the university is subsidized based upon its capacity utilization, the predicted duration of the remaining educational process can be transformed into a monetary value (customer value). If applicable, tuition fees should be considered, too.

\section{„Share-of-wallet“}

The "Share-of-wallet" (of a company regarding a specific customer) is the expected/predicted percentage of the customer's total demand of a specific product group the company can achieve [15, p. 111]. Adapted to the environment at hand, the "Share-of-education" is the part of the educational process of a person/customer a university can achieve.

\section{Cross-/up-selling}

Related to products/services the customers has already bought or agreed to buy, crossand up-selling is an action to increase the "Share-of-wallet" by offering/selling complementary products/services (cross-selling) or products/services with a higher contribution margin (up-selling) to the customer. These concepts can be adapted as follows:

- Cross-selling: Offering services that broaden an ongoing or completed education (complementary services), can be interpreted as cross-selling. An example is to offer a leadership coaching to master students.

- Up-selling: Based on the academic level a student has already achieved, he or she can be offered additional educational services. Offering a master program to students with a bachelor degree can be classified as up-selling.

\section{One-stop-shopping}

Closely related to the concept of cross-selling is „one-stop-shopping“. The goal is to satisfy a customer's multiple and complementary demands in one (virtual) place. Adapted to institutions of higher education "one-stop-shopping" means to offer all services for program members through a single user interface such as, for example, a web portal.

Fig. 1 shows on the right hand side ("Perspective of a University") which steps are suitable for cross-selling. Furthermore, the hypothesis is presented that services in acquisition phase I and education phase I influence the probability of successful upselling in acquisition phase II: The better the university's services during the bachelor studies are, the higher the probability is that the student applies to a following program at the same university. 


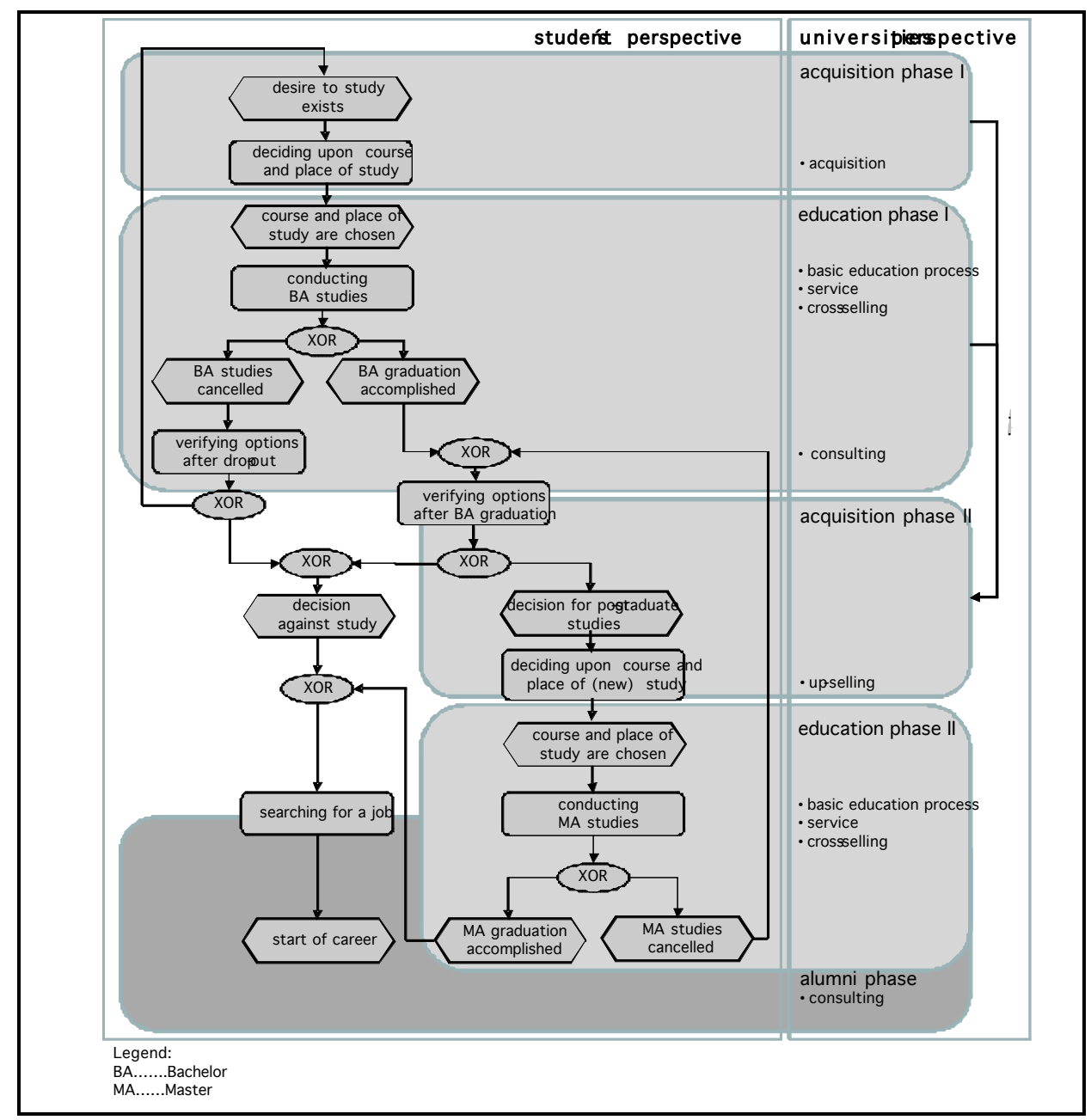

Fig. 1: Educational process throughout bachelor and master programs

Applying the term customer here as well as transferring CRM concepts to universities has limitations. A corresponding comparison between companies and institutions of higher education can be found in Fig. 2. Besides varying objectives and retention strategies, the target groups or, more precisely, the rationale leading to target groups for CRM actions differ. Enterprises are implementing selective CRM strategies [17, p. 3]; actions for customer retention are applied to (potentially) profitable customer relations only. For universities this would mean to offer certain services only to a subset of their students selected basing on their "customer value". Taking into account the goals of the Bologna declaration, such a strategy cannot be applied, at least not at government funded universities. 


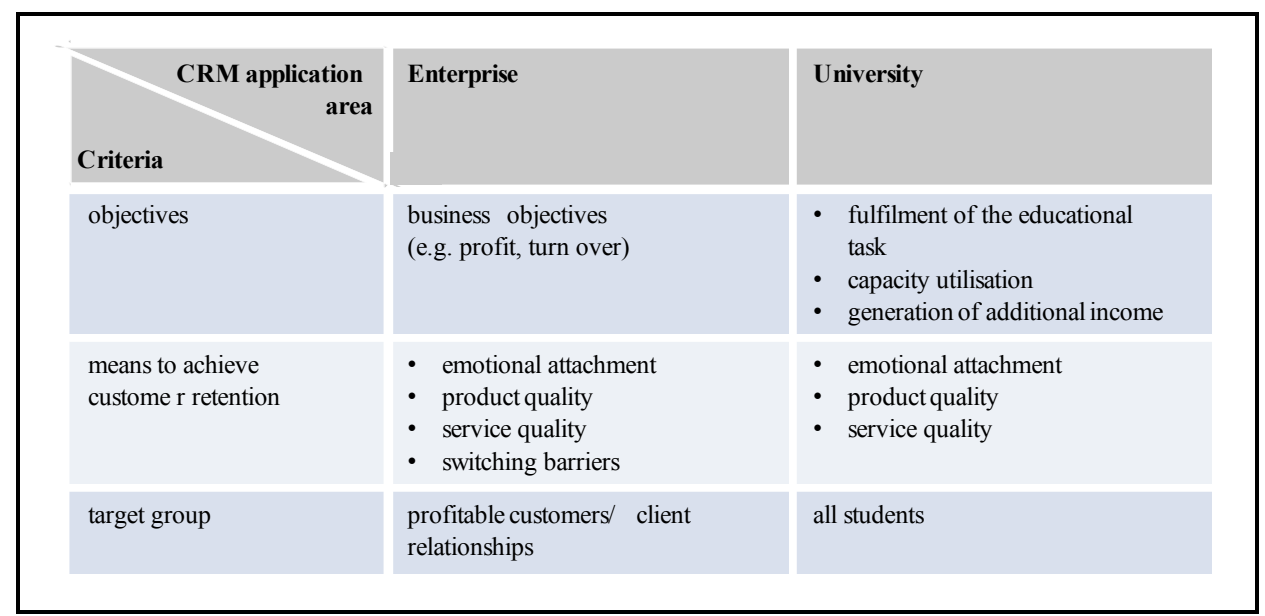

Fig. 2: Comparison of CRM concepts deployed by enterprises and universities

\section{Designing an Integration Architecture for the Deployment of CRM at Universities}

In this section central requirements are being outlined that have to be met when implementing a CRM strategy at a university. The discussion is restricted to the support of bachelor and master programs, i.e. functions "BA studies accomplished" and "MA studies accomplished" of the event-driven process chain presented in Fig. 1. Covering additional educational phases (e.g. accomplishing two bachelor programs) are possible too. In the following, an architecture is presented that can integrate new systems (especially for CRM functionality) and legacy systems.

\subsection{Requirements}

A CRM strategy for institutions of higher educational has to solve two core problems. On the one hand, isolated service processes of different organizational units have to be aligned. Integrating the services towards a coherent overall process should be done by the university (,One-Stop-Shopping“) and not by the students. The entire educational process could be event-driven. The subscription to a specific program could automatically trigger other processes, e.g. the display of related classes offered in the current semester. Depending on the student's choice other services could follow.

On the other hand, following a successful integration - and this is the specific potential of this approach - additional value added services could be offered in order to intensify the student's relationship with the university. Examples for those services are personalized messages regarding:

- subscription deadlines of classes relevant to the individual student,

- classes that complement classes the student has already attended, 
- developments in the educational process (academic performance) endangering successful studies toward the degree,

- guest lectures and other events which are, based on their content and related to the current course of study, especially relevant to the student,

- employment opportunities fitting to the educational status,

- location changes or class cancellations.

It is possible to deliver these messages by SMS or E-Mail. Some universities in Europe already offer such services. ${ }^{1}$

\subsection{Architectural outline}

To be able to implement the requirements mentioned above, the university's IT systems have to be connected. Especially, data about the students from existing and separated data sources have to be integrated into a consistent customer view. In the following we illustrate in detail the functionality of the architecture depicted in Fig. 3.

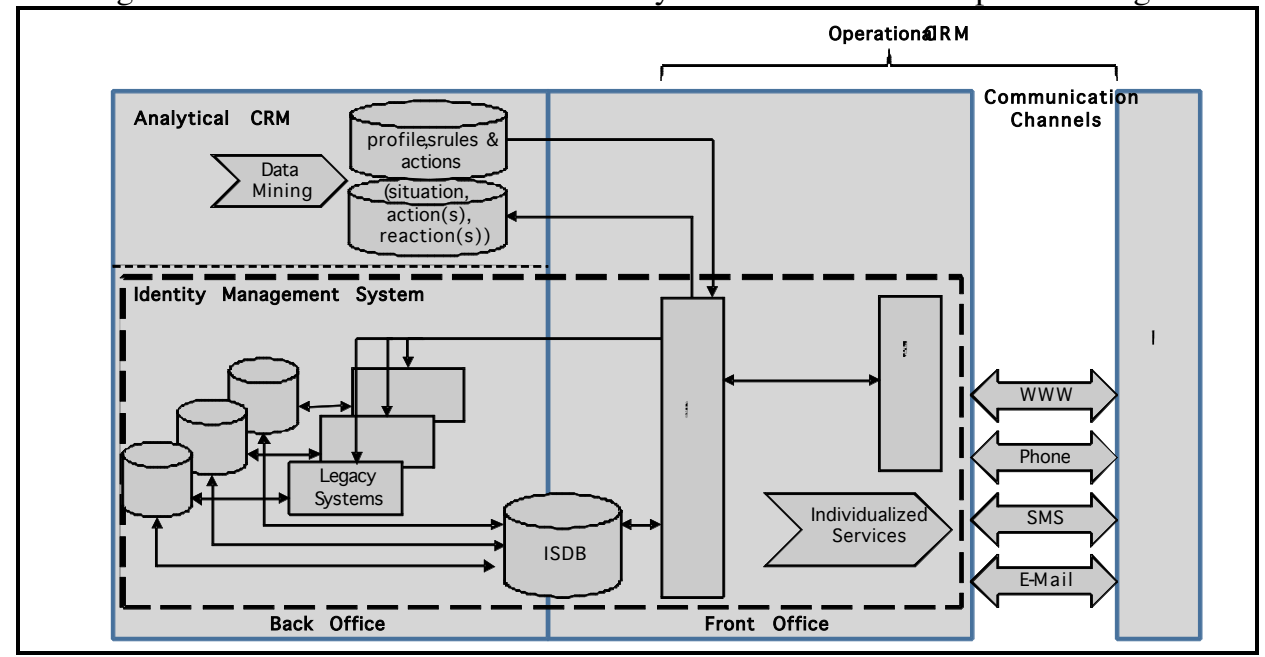

Fig. 3: Architecture for the implementation of CRM concepts at universities

The core of the architecture is an integrated student data base (ISDB). It is the interface between the back office and front office systems and contains all integrated data on the students. The ISDB should be synchronized on time with the legacy systems (examination office system etc.) to assure short refresh periods. If the legacy systems provide sufficient availability (up time) and accessibility the ISDB can be implemented as a federated database system thus avoiding data replication.

In an additional database (depicted in the left hand side of the figure) profiles, rules and actions are stored to compare individual student data with the profiles to de-

1 http://www.ethbib.ethz.ch/service/sms.html;

http://www.ub.uni-passau.de/e-mailbenachrichtigung.html; http://www.isu.uzh.ch/cms/marketing/marketingmanagement/elearning/smsservice.html, https://unisms.unisg.ch/ 
duct and take, based on the rules, specific actions. The profiles are generalized situations with assigned actions. The actions are designed to provide services (value) to the students that fit to their current situation.

Generating these profiles, rules and actions, which are part of analytical CRM, can be based on hypotheses in a first step. Later on, it is possible to deduct information of the CRM actions and the students' reactions with data mining techniques. These data (tuple "situation, action(s), reaction(s)") are transferred through the CRM system to the analytical CRM system and processed. The outcome of this feedback is a so called "closed loop", that can be used for the individualized services, e.g. in a call center or for generating SMS and e-mails. The use of e-business actions at universities was already suggested by Kidwell et al. in "Is Your Campus Ready for E-Business?" [13, p. 27].

Process integration can be achieved by implementing a workflow management component. This component is included in the described architecture and assures that processes initialized by the students are connected seamlessly. At the same time the students can use a web portal (which uses information from the CRM system) providing access to the back office legacy systems. Thus, comfortable self service functions can be used and challenges for first year students as described by Heiling are eliminated [7, p. 44]. Additionally, a full service accessible at a single point is offered [7, p. 53] ("one-stop-shopping").

The architecture outlined above does not differ fundamentally from CRM architectures in the commercial area; the use of standard components (CRM software, portal technology) is possible. The main challenges are to compose reasonable service processes, to integrate the data of the different applications, and of course to fulfill the requirements mentioned before in chapter 5.1.

\section{Future Work and Conclusion}

The architecture presented in this paper is very similar to common CRM architectures. The increasing competition resulting from the Bologna process forces universities to transform themselves into educational service providers for students. This transformation will eventually lead to the adaptation and implementation of CRM concepts. Universities can achieve unique selling propositions and enhance student retention by means of advanced CRM methods such as, for example, data mining. It can be expected that this will render innovative services to students possible in the near future.

Besides a refinement of the architecture and an evaluation how the typical legacy systems at universities can be coupled with state-of-the-art CRM applications, the retention effect has to be further investigated and verified. It is intuitively plausible that student-centered educational processes are causing this effect; also the first empirical results are showing this (compare [18] as well as the results of the Technical University of Dresden [19, p. 33]). Nevertheless, further research has to be done on the students' perception of integrated and innovative services as added value and on assumed retention effects. 
The adaptation of CRM concepts at a university raises privacy protection issues especially when academic record data is involved. Therefore, retention efforts through CRM are dependent on the students' consent to integrate and analyze their data. It has to be investigated if students are concurring with such a use of their data.

Based on the presented concepts the term "customer" can be extended to cover additional groups of stakeholders [20], e.g. companies using the universities' educational services for personnel development.

Finally, the assumption can be made, that implementing CRM concepts at a university also has positive effects on winning and retaining academic and professional personnel, because a professional working environment can be provided and administrative work can be done more easily. This hypothesis should also be proved by empirical research.

\section{Bibliography}

1. Bologna Declaration of 19 June 1999: Joint declaration of the European Ministers of Education. http://www.bologna-berlin2003.de/pdf/bologna_declaration.pdf. Accessed 21 April 2008

2. Rektorenkonferenz der Schweizer Universitäten (CRUS): Regelung für die Zulassung zu den Spezialisierten Masterstudiengängen an den schweizerischen Universitäten. www.crus.ch/dms.php?id=2285. Accessed 21 April 2008 (in German)

3. Ferriss A L (1965) Predicting Graduate Student Migration. In: Social Forces 43 (3):310319

4. Teichler U, Jahr V (2001) Mobility During the Course of Study and After Graduation. European Journal of Education 36 (4):443-458

5. Briedis K (2005) Der Bachelor als Sprungbrett? Erste Ergebnisse zum Verbleib von Absolventen mit Bachelorabschluss. In: Leszczensky M, Wolter A (ed.) Der Bologna-Prozess im Spiegel der HIS-Hochschulforschung, Kurzinformation HIS, Hannover (in German)

6. Amrhein D (1998) Die Universität als Dienstleistungsunternehmen, Deutscher Universitäts-Verlag, Wiesbaden (in German)

7. Heiling J (2004) Studierendenzentrierte Dienstleistungen. In: Zentrale Studienberatung der Universität Hannover (ed.) Ressourcenorientierte Studienberatung - zwischen methodischem Konzept und ökonomischem Kalkül, Proceedings „Fachtagung der Gesellschaft für Information, Beratung und Therapie an Hochschulen e.V. GIBeT" 3rd to 6th of March 2004, pp. 61-75 (in German)

8. Kudrass $\mathrm{T}$ (2005) Integration heterogener Datenbanken am Beispiel eines HochschulInformationssystems. In: Jantke K P, Fähnrich K P, Wittig W S (ed.) Marktplatz Internet: Von e-Learning bis e-Payment, Proceedings 13th LIT 2005 (13. Leipziger InformatikTage) Bonner Köllen, Bonn, pp. 287-296 (in German)

9. Pausits A (2006) Student Relationship Management in der akademischen Weiterbildung Dissertation, Universität Flensburg (in German)

10. Tapp A, Hicks K, Stone M (2004) Direct and database marketing and customer relationship management in recruiting students for higher education. In: International Journal of Nonprofit and Voluntary Sector Marketing 9 (4):335-345

11. Seidman A (1991) The Evaluation of a Pre/Post Admissions/Counseling Process at a Suburban Community College: Impact on Student Satisfaction with the Faculty and the Institution, Retention, and Academic Performance. In: College and University 66 (4):223-232

12. Tinto V (1998) Colleges as Communities: Taking Research on Student Persistence Seriously. In: The Review of Higher Education 21(2):167-177 
13. Kidwell J, Mattie J, Sousa M (2000) Prepare your Campus for E-Business - Tips for crafting a successful strategy. In: Educause Quarterly 2:21-29

14. Rapp R (2000) Customer Relationship Management. Campus, Frankfurt/New York (in German)

15. Gerth N (2001) Zur Bedeutung eines neuen Informationsmanagements für den CRMErfolg. In: Link J (ed.) Customer Relationship Management. Springer, Berlin et al. (in German)

16. Scheer A W (2000) ARIS - Business Process Modeling. Springer, Berlin et al.

17. Link J (2001) Grundlagen und Perspektiven des Customer Relationship Management. In: Link J (ed.) Customer Relationship Management. Springer, Berlin et al. (in German)

18. Wyss, A.: Kundenbeziehungsmanagement im universitaeren Bereich: Eine empirische Untersuchung zur Wirksamkeit von Kundenbeziehungsmassnahmen. Lizentiatsarbeit, Institute of Information Systems, University of Bern 2006 (in German).

19. Festge F, Meyer M, Schwaiger M (2005) Die Zufriedenheit mit dem Studium der Betriebswirtschaftslehre an der Technischen Universität Dresden. Schriften zur Empirischen Forschung und Quantitativen Unternehmensplanung. 22.2005, LudwigMaximilians-Universität München (in German)

20. Fayerman M (2002) Customer Relationship Management. In: New Directions for Institutional Research 113:57-67 